\title{
Mathematical Model Research on Contribution of Higher Education to Economic Growth
}

\author{
Dao Zhou \\ Hunan International Business Vocational College, 410201 Changsha Hunan, China
}

\begin{abstract}
This paper selects 31 provinces (autonomous regions and municipalities) of China and divides them into three areas with four indicators-economic output, physical capital input, labor input and education years in 2004 to 2013 as data samples and adopts the theory of aggregate production function and least square method to establish a mathematical model of the relationship between education and economic growth, and concludes the following conclusion: The rate of China's education contribution towards economic growth is $9.82 \%$. The economic growth rate of human capital level for education per capita in the eastern area is $11.513 \%$, which is higher than the national average level, while the economic growth rate of education in the central and western area is respectively $9.221 \%$ and $5.479 \%$, which is lower than the national average level.
\end{abstract}

Keywords. area; aggregate production function; least square method; growth rate

\section{Introduction}

A lot of people carry out related research on the relationship between education and economic growth. Qu Zhensen ${ }^{[1]}$ adopts the data samples of China in 1952-1978, and utilizes the labor simplification method in total hours of working years, so as to conclude that the rate of education contribution towards economy is $20.7 \%$. In 1990, Han Zongli ${ }^{[2]}$ adopts two research samples in 1964-1982 and in 1982-1987, and utilizes the labor simplification method of education years, but reaching different results. The rates of education contribution towards economy during two periods are respectively $35.43 \%$ and $10.26 \%$. In 1999 , Shen Lisheng ${ }^{[3]}$ adopts the research samples in 1982-1995 and utilizes the production function method, so as to calculate that the rate of education contribution towards economy is $30.6 \%$. In 2006, Tan Yongsheng ${ }^{[4]}$ adopts the research samples in 1978-2003 and utilizes the production function method, so as to calculate that the rate of education contribution towards economy is $25.72 \%$.

This paper utilizes the aggregate production function, and gives full consideration to four factors--economic output, physical capital input, labor input and education factor, so as to establish a mathematical model of the relationship between education and economic growth. 


\section{Modeling and solution}

\subsection{General situation of China's education}

This paper selects the data ${ }^{[5]}$ of total funds for education and gross national product (GDP) of China in 2003-2012 as shown in Table 1 and Figure 1, so as to roughly understand China's education.

Table 1. Total funds for education and gross national product (GDP) in 2003-2012 (unit: 100 million yuan)

\begin{tabular}{lll}
\hline Year & TFE & GDP \\
\hline 2003 & 6208.27 & 134977.0 \\
2004 & 7242.60 & 159453.6 \\
2005 & 8418.84 & 183617.4 \\
2006 & 9815.31 & 215904.4 \\
2007 & 12148.07 & 266422.0 \\
2008 & 14500.74 & 316030.3 \\
2009 & 16502.71 & 340320.0 \\
2010 & 19561.85 & 399759.5 \\
2011 & 23869.29 & 468562.4 \\
2012 & 27695.97 & 518214.7 \\
\hline
\end{tabular}

Note: TFE: Total Funds for Education; GDP: Gross Domestic Product

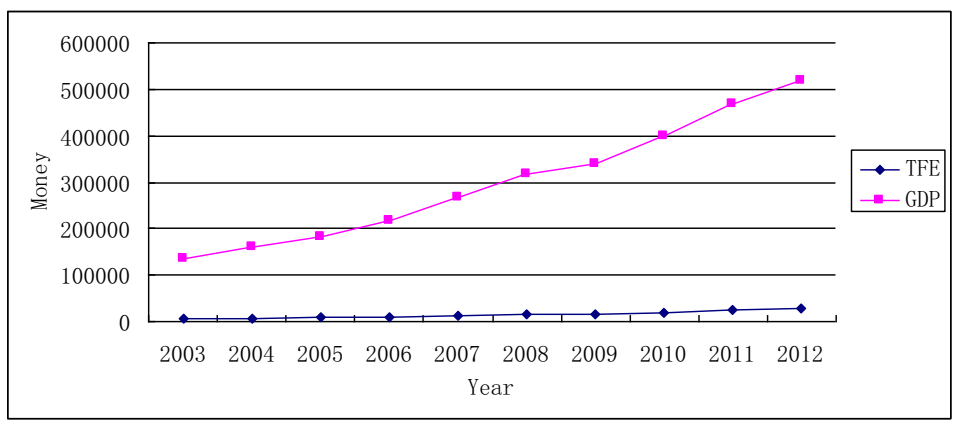

Figure 1. Diagram of total funds for education and gross national product (GDP) in 2003-2012.

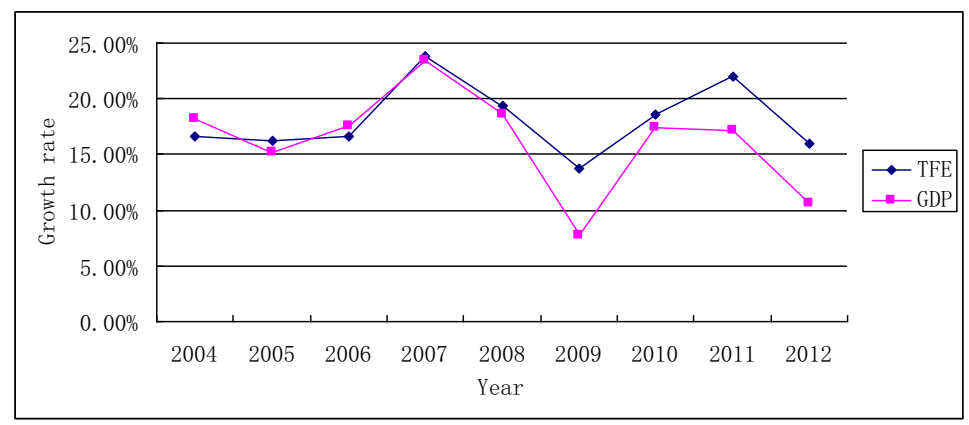

Figure 2. Diagram of growth rate of total funds for education and gross national product in China in 2004-2012. 
As shown in Figure 1, the total funds for education in China are much less than the gross national product.

The growth rate of total funds for education and gross national product in China in 2003-2012 is shown in Figure 2.

As shown in Figure 2, the total funds for education will increase with the increase of the growth rate of gross national product, and decrease with the decrease of the growth rate of gross national product. On the whole, the growth rate of the total funds for education is higher than that of the gross national product.

\subsection{Aggregate production function model}

The production function reflects the relationship between the input and output quantity in the production process, and it also reflects the input quantity of various production factors required by a certain output. Assuming that $Y$ is the output, $X_{i}$ is the input quantity $(i=1,2, \cdots, n)$ of the production factor $i$, then the production function is:

$$
Y=F\left(X_{1}, X_{2}, \cdots, X_{n}\right)
$$

This function must meet the continuity and smoothness (the marginal output $\frac{\partial F}{\partial X_{i}}$ is meaningful), the monotony $\left(\frac{\partial F}{\partial X_{i}}>0\right)$ convexity (the decreasing marginal output $\frac{\partial^{2} F}{\partial_{i}^{2}}<0$ ) and the homogeneity $\left(F\left(\lambda X_{1}, \lambda X_{2}, \cdots, \lambda X_{n}\right)=\lambda^{h} F\left(\lambda X_{1}, \lambda X_{2}, \cdots, \lambda X_{n}\right)\right)$ and so on.

According to the endogenous economic growth theory, the following model is proposed based on the C-D production function:

$$
Y_{t}=A_{t} K_{t}^{\alpha} L_{t}^{\beta} E_{t}^{\gamma} e^{u_{t}}
$$

Where: $Y_{t}$ is the economic output in the period $t ; L_{t}$ is the labor input in the period $t$; $E_{t}$ is the education level in the period $t ; u_{t}$ is a random disturbance term.

\subsection{Calculation of the factor contribution rate}

To remove the random disturbance term and subscript $t$ in the formula (1), and view $Y$ as multivariate functions of $K, L$ and $E$, taking the natural logarithm of the formula to obtain:

$$
\ln Y=\ln A+\alpha \ln K+\beta \ln L+\gamma \ln E
$$

The total differential of the above formula is: $\frac{d Y}{Y}=\alpha \frac{d K}{K}+\beta \frac{d L}{L}+\gamma \frac{d E}{E}$

Where: $d Y / Y$ is the economic growth rate; $d K / K, d L / L$ and $d E / E$ are respectively the growth rate of the fixed capital stock, labor input and education level.

Assuming that $X_{0}$ is the level in the first period, $X_{i}(i=1,2, \cdots, n)$ is the level in the period $i$, then $X_{i} / X_{i-1}(i=1,2, \cdots, n)$ is the development speed of the variable $X$ with link-relative method, and the annual growth rate of $X$ is: 


$$
r_{X}=\sqrt{\frac{X_{1}}{X_{0}} \cdot \frac{X_{2}}{X_{1}} \cdots \cdots \frac{X_{n}}{X_{n-1}}}-1=\sqrt{\frac{X_{n}}{X_{0}}}-1
$$

Therefore, if the output elasticity of production factor $X$ is $\varepsilon$, the growth rate is $r_{X}$, and the economic growth rate is $r_{Y}$, then the rate of contribution of the factor $X$ to economic growth is:

$$
P_{e}=\frac{\varepsilon \cdot r_{X}}{r_{Y}}
$$

\subsection{Sample data selection}

\subsubsection{Sample selection}

According to the Bulletin of the National Bureau of Statistics in 2005, 31 mainland provinces in China are divided into three major economic areas as shown in Figure 3. The unit of data samples is province, and the time is from 2004 to 2013.

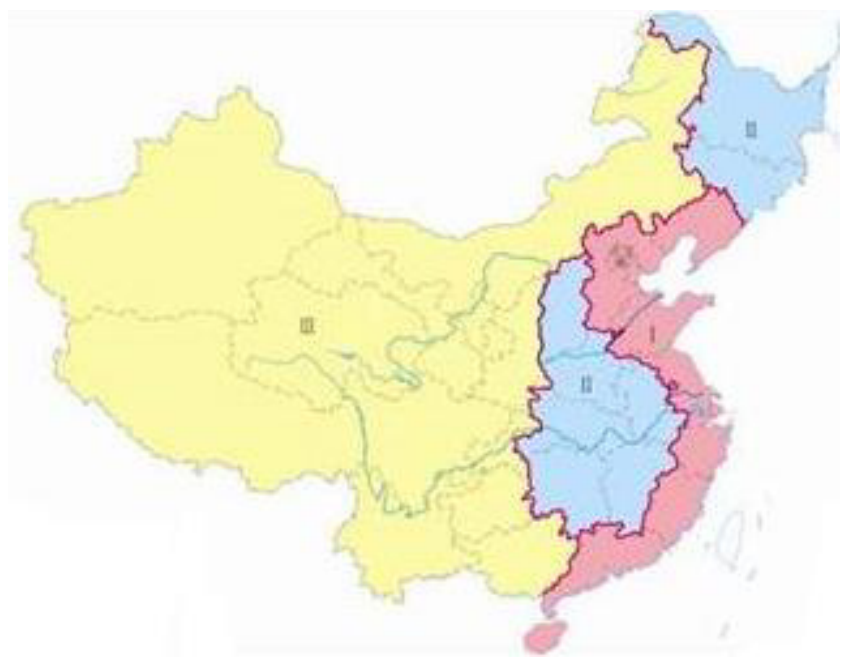

Figure 3. China's three major economic zones. (Note: I is the eastern area; II is the central area; III is the western area)

\subsubsection{Measurement of each indicator ${ }^{[6]}$}

According to the above model, the identified indicators are: economic output, physical capital input, labor input and education factor. The economic output is expressed by the actual GDP; the physical capital input is expressed by the data of fixed asset investment of society; the number of labor is used to measure the number of labor input; the education year is used to measure the education factor.

\subsubsection{Data of each measuring factor ${ }^{[5]}$}

(1) Economic output 
Table 2. Economic output per capita in each area in 2004 - 2013 (unit: RMB)

\begin{tabular}{llll}
\hline Year & East & Central & West \\
\hline 2004 & 99494.72 & 39488.97 & 28603.48 \\
2005 & 117933.65 & 46362.07 & 33493.31 \\
2006 & 137542.33 & 53446.17 & 39495.78 \\
2007 & 163369.87 & 64390.61 & 47864.14 \\
2008 & 191041.13 & 77922.09 & 58256.58 \\
2009 & 211886.90 & 86443.31 & 66973.48 \\
2010 & 250487.94 & 105145.56 & 81408.49 \\
2011 & 293581.45 & 127624.70 & 100234.96 \\
2012 & 320738.47 & 141908.57 & 113904.80 \\
2013 & 349336.54 & 154670.02 & 126002.78 \\
\hline
\end{tabular}

(2) Physical capital input

Table 3. Physical capital input in each area in 2004- 2013 (unit: 100 million yuan)

\begin{tabular}{llll}
\hline Year & East & Central & West \\
\hline 2004 & 40411.5 & 15129.0 & 13754.4 \\
2005 & 49826.7 & 19623.9 & 17645.0 \\
2006 & 60326.8 & 25726.9 & 21996.9 \\
2007 & 72311.2 & 34231.0 & 28250.9 \\
2008 & 87754.6 & 45390.1 & 35948.8 \\
2009 & 107840.5 & 61292.2 & 49686.3 \\
2010 & 131897.0 & 77573.5 & 61892.2 \\
2011 & 147989.2 & 85740.7 & 72104.0 \\
2012 & 173758.7 & 105821.1 & 89008.6 \\
2013 & 204205.2 & 127172.6 & 109260.9 \\
\hline
\end{tabular}

(3) Labor input

Table 4. Labor input in each area in 2004 - 2013 (unit: 10,000 persons)

\begin{tabular}{llll}
\hline Year & East & Central & West \\
\hline 2004 & 25748.7 & 21482.1 & 19078.3 \\
2005 & 26788.7 & 21790.7 & 19448.0 \\
2006 & 27758.5 & 22150.5 & 19792.6 \\
2007 & 28836.5 & 22384.5 & 20129.8 \\
2008 & 29721.1 & 22737.0 & 20493.2 \\
2009 & 30836.0 & 23286.7 & 20838.5 \\
2010 & 31571.0 & 23975.8 & 21287.6 \\
2011 & 32673.2 & 24190.3 & 21598.1 \\
2012 & 33655.8 & 24614.1 & 21959.2 \\
2013 & 34638.4 & 25038.0 & 22320.3 \\
\hline
\end{tabular}

(4) Education factor 
Table 5. Education year per capita in each area in 2004 - 2013 (unit: person)

\begin{tabular}{llll}
\hline Year & East & Central & West \\
\hline 2004 & 9.32 & 8.57 & 7.52 \\
2005 & 9.24 & 8.47 & 7.25 \\
2006 & 9.55 & 8.78 & 7.61 \\
2007 & 9.68 & 8.87 & 7.75 \\
2008 & 9.82 & 8.97 & 7.89 \\
2009 & 9.97 & 9.08 & 8.03 \\
2010 & 10.11 & 9.18 & 8.17 \\
2011 & 10.25 & 9.29 & 8.31 \\
2012 & 10.39 & 9.39 & 8.46 \\
2013 & 10.53 & 9.49 & 8.60 \\
\hline
\end{tabular}

\subsection{Solution to model}

\subsubsection{Aggregate production function}

The aggregate production function model is established by the use of the formula (2). Taking the eastern area as an example, the multiple linear fitting is carried out by the use of the least square method, and then the data processing results are shown in Table 6:

Table 6. Logarithmic results of each indicator

\begin{tabular}{lllll}
\hline Year & $\ln Y$ & $\operatorname{lnK}$ & $\operatorname{lnL}$ & $\ln \mathrm{C}$ \\
\hline 2004 & 11.51 & 10.61 & 10.16 & 2.23 \\
2005 & 11.68 & 10.82 & 10.20 & 2.22 \\
2006 & 11.83 & 11.01 & 10.23 & 2.26 \\
2007 & 12.00 & 11.19 & 10.27 & 2.27 \\
2008 & 12.16 & 11.38 & 10.30 & 2.28 \\
2009 & 12.26 & 11.59 & 10.34 & 2.30 \\
2010 & 12.43 & 11.79 & 10.36 & 2.31 \\
2011 & 12.59 & 11.90 & 10.39 & 2.33 \\
2012 & 12.68 & 12.07 & 10.42 & 2.34 \\
2013 & 12.76 & 12.23 & 10.45 & 2.35 \\
\hline
\end{tabular}

\subsubsection{Regression analysis algorithm}

(1) Multiple linear regression model ${ }^{[7]}$ :

Assuming that between the dependent variable $y$ and the independent variables $x_{1}, x_{2}$ and $x_{3}$ is:

$$
y=b_{0}+b_{1} x_{1}+b_{2} x_{2}+b_{3} x_{3}
$$

Where: $y$ is an observable random variable; $b_{0}, b_{1}, b_{2}, b_{3}$ are unknown parameters; $\varepsilon$ is an unobservable random error, and meets $E_{\varepsilon}=0, D(\varepsilon)=\sigma^{2}\left(\sigma^{2}\right.$ unknown), but the random error of $\varepsilon$ is small, so it is not considered with respect to the reality. 
Based on 10 sets of data, $\left(y_{j}, x_{1 j}, x_{2 j}, x_{3 j}\right)(j=1,2, \cdots, 10)$, where: $x_{i j}$ is the value $j$ of the independent variable $x_{i} ; y_{j}$ is the value $j$ of the dependent variable $y$, which is substituted into the formula (1) to obtain the data structural formula of the model:

$$
\left\{\begin{array}{l}
y_{1}=b_{0}+b_{1} x_{11}+b_{2} x_{21}+b_{3} x_{31} \\
y_{2}=b_{0}+b_{1} x_{12}+b_{2} x_{22}+b_{3} x_{32} \\
\vdots \\
y_{n}=b+b_{0} x_{1 n}+b_{1} x_{2 n}+b_{3} x_{3 n}
\end{array}\right.
$$

The above formula can be expressed by the matrix as:

$$
\begin{gathered}
Y=\left[\begin{array}{l}
y_{1} \\
y_{2} \\
\vdots \\
y_{n}
\end{array}\right] \quad X=\left[\begin{array}{cccc}
1 & x_{11} & \cdots & x_{41} \\
1 & x_{12} & \cdots & x_{42} \\
\vdots & \vdots & \ddots & \vdots \\
1 & x_{1 n} & \cdots & x_{4 n}
\end{array}\right] \quad B=\left[\begin{array}{l}
b_{0} \\
b_{1} \\
\vdots \\
b_{n}
\end{array}\right] \\
Y=X B
\end{gathered}
$$

(2) Estimation of unknown parameters

By the use of the least square method, according to SPSS software ${ }^{[8]}$ :

$$
b_{0}=-6.847 \quad b_{1}=0.537 \quad b_{2}=1.094 \quad b_{3}=0.701
$$

Therefore, the multiple linear regression equation is:

$$
y=0.537 x_{1}+1.094 x_{2}+0.701 x_{3}-6.847
$$

That is: $\ln Y=0.537 \ln K+1.094 \ln L+0.701 \ln E-6.847$

(3) Significance test of regression equation Specific steps are as follows:

I. Propose null hypothesis and alternative hypothesis

\begin{tabular}{|c|c|c|c|c|c|}
\hline Model & Sum of Squares & df & Mean Square & $\mathrm{F}$ & Sig. \\
\hline Regression & 1.670 & 3 & .557 & 477.620 & $.000^{\mathrm{a}}$ \\
\hline Residual & .007 & 6 & .001 & & \\
\hline Total & 1.677 & 9 & & & \\
\hline
\end{tabular}

$$
\begin{gathered}
H_{0}: b_{i j}=0,(i=1,2,3,4 ; j=1,2, \cdots .10) \\
H_{1}: b_{i j} \text { is partially } 0,(i=1,2,3,4 ; j=1,2, \cdots, 10)
\end{gathered}
$$

II. According to Table 7, $\mathrm{F}$ value is 477.620 . If given $\alpha=0.01$, then $\mathrm{p}<\alpha$, so $\mathrm{H}_{0}$ is rejected, considering that the linear relation of regression equation is significant.

Table 7. Analysis of variance (ANOVA)

a. Predictors: (Constant), $\ln \mathrm{E}, \ln \mathrm{L}, \ln \mathrm{K}$

b. Dependent Variable: $\ln \mathrm{Y}$ 
(4) Test of regression coefficients Specific steps are as follows:

I. Propose the null hypothesis and the alternative hypothesis:

$$
\begin{aligned}
& H_{0}: b_{j}=0(j=1,2, \cdots, 10) \\
& H_{1}: b_{j} \neq 0(j=1,2, \cdots, 10)
\end{aligned}
$$

II. Carry out the significance test for each regression coefficient:

Table 8. Coefficients

\begin{tabular}{|ll|l|l|l|l|l|}
\hline \multirow{2}{*}{ Model } & \multicolumn{2}{|l|}{ Unstandardized Coefficients } & Standardized Coefficients & \multirow{2}{*}{} & \multirow{2}{*}{ Sig. } \\
\cline { 2 - 5 } & $\mathrm{B}$ & Std. Error & Beta & $\mathrm{t}$ & \\
\hline 1 & (Constant) & -6.847 & 20.958 & & -.327 & .055 \\
& $\ln \mathrm{K}$ & .537 & .456 & .681 & 1.177 & .004 \\
$\ln$ & 1.094 & 2.529 & .245 & .433 & .080 \\
$\ln$ & .701 & 1.488 & .073 & .471 & .001 \\
\hline
\end{tabular}

a. Dependent Variable: $\ln Y$

Sig of three variables $-\ln K, \ln L$ and $\ln E$ in Table 8 are respectively $0.004,0.080$ and 0.001 . If given $\alpha=0.01$

$p_{1}=0.004<\alpha$, and $H_{0}$ is rejected, then the regression coefficient of independent variable $(\mathrm{lnE})$ is significant;

$p_{2}=0.080>\alpha$, and $H_{0}$ is accepted, then the regression coefficient of independent variable $(\operatorname{lnL})$ is not significant;

$p_{3}=0.001<\alpha$, and $H_{0}$ is rejected, then the regression coefficient of independent variable $(\operatorname{lnK})$ is significant.

\section{Normal P-P Plot of Regression Standardized Residual}

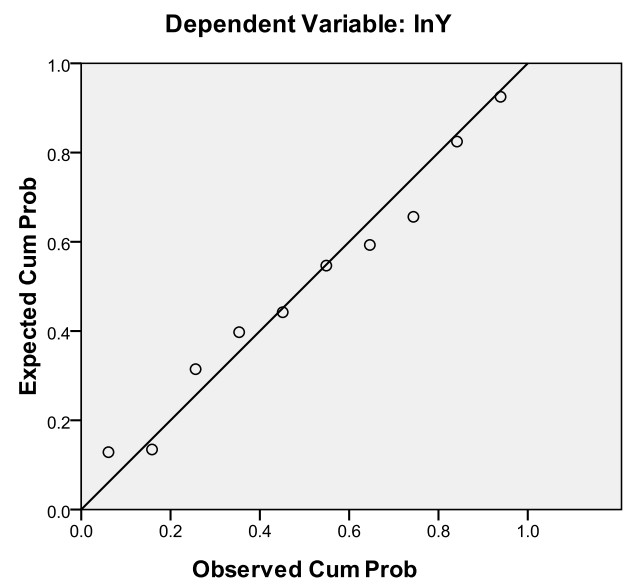

Figure 4. P-P diagram. 
Figure 4 shows that the majority of points are close to the diagonal, so standardized residuals follow normal distribution.

Similarly, the regression results in each area can be calculated as shown in Table 9:

Table 9. Regression results in each area

\begin{tabular}{llllll}
\hline Area & $\ln \mathrm{A}$ & $\operatorname{lnK}$ & $\ln \mathrm{ln}$ & $\ln$ & R Square \\
\hline East & -6.847 & 0.537 & 1.094 & 0.701 & 0.996 \\
Central & -20.160 & 0.434 & 2.509 & 0.713 & 0.992 \\
West & -43.048 & 0.311 & 4.940 & 0.817 & 0.998 \\
\hline
\end{tabular}

Dependent Variable: $\ln Y$

\subsubsection{Calculation of contribution rate}

Table 10. Annual growth rate of each variable in each area (\%)

\begin{tabular}{lllll}
\hline Area & GDP & K & L & E \\
\hline East & 10.834 & 12.323 & 1.253 & 5.776 \\
Central & 10.112 & 11.594 & 1.054 & 5.213 \\
West & 9.787 & 11.421 & 0.996 & 4.989 \\
\hline
\end{tabular}

The rate of contribution of production factor in each area to economic growth can be calculated by the formula (3). The results are shown in Table 11:

Table 11. Rate of contribution of factors in each area to economic growth (\%)

\begin{tabular}{lllll}
\hline Area & $\mathrm{K}$ & $\mathrm{L}$ & $\mathrm{E}$ & TFP \\
\hline East & 81.484 & 2.16 & 11.513 & 4.843 \\
Central & 87.394 & 1.164 & 9.221 & 2.221 \\
West & 90.26 & 0.146 & 5.479 & 4.114 \\
\hline
\end{tabular}

Note: TFP (Total Factor Productivity) is the total factor productivity.

\section{Conclusion}

We can conclude the following conclusions from this research: The rate of China's education contribution towards economic growth is $9.82 \%$. The economic growth rate of human capital level for education per capita in the eastern area is $11.513 \%$, which is higher than the national average level; the economic growth rate of education in the central and western area is respectively $9.221 \%$ and $5.479 \%$, which is lower than the national average level. Therefore, it is recommended to increase the education investment and the benefits of education investment, promote harmonious development of inter-regional education and economic growth, and especially increase efforts to support the western area.

\section{References}

1. Wang Shanmai. 1996. Education Input and Output Research. Shijiazhuang: Hebei Education Press, pp: 234-236+237-240.

2. Han Zongli. 1990. Exploration and evaluation of social and economic benefits in China's education investment. Education and Economy, (1): 13-17.

3. Shen Lisheng \& Zhu Yunfa. 1999. Analysis of human capital and economic growth. Beijing: Social Sciences Academic Press. 
4. Tan Yongsheng. 2006. Empirical research on measurement of human capital formed by education and its contribution to China's economic growth. Education and Econo$m y,(1): 33-36$.

5. http://www.stats.gov.cn/tjsj/ndsj/2014/indexce.htm

6. Ye Maolin \& Zheng Xiaoqi, et al. 2003. Quantitative analysis of the contribution of education to economic growth. Quantitative \& Technical Economics, (1): 89-92.

7. Wan Xinghuo. 2007. Probability Theory and Mathematical Statistics. Beijing: Science Press.

8. Gao Xiangbao \& Dong Hanqing. 2007. Data Analysis and SPSS Application. Beijing: Tsinghua University Press. 